\begin{tabular}{|c|l|}
\hline Title & Karyoty pic Evolution of A podemus (Muridae, Rodentia) Inferred from Comparative FISH A nalyses \\
\hline Author(s) & Matsubara, Kazumi; Nishida U mehara, Chizuko; Tsuchiya, Kimiyuki; Nukaya, Daiki; Matsuda, Yoichi \\
\hline Citation & $\begin{array}{l}\text { Chromosome Research, 12(4),383-395 } \\
\text { https://doi.org/40.1023/B:CHRO.000034103.05528.83 }\end{array}$ \\
\hline Issue Date & 2004 05 \\
\hline Doc URL & http://hdl.handle.net/2115/30317 \\
\hline Rights & The original publication is available at www.springerlink.com \\
\hline Type & article (author version) \\
\hline File Information & CR12-4.pdf \\
\hline
\end{tabular}

Instructions for use 


\section{Karyotypic evolution of Apodemus (Muridae, Rodentia) inferred from comparative FISH analyses}

Kazumi Matsubara ${ }^{1}$, Chizuko Nishida-Umehara ${ }^{1,2,3}$, Kimiyuki Tsuchiya ${ }^{4}$, Daiki Nukaya $^{5}$ and Yoichi Matsuda ${ }^{1,2,3}$

${ }^{1}$ Laboratory of Cytogenetics, Division of Bioscience, Graduate School of Environmental Earth Science, Hokkaido University, North 10 West 8, Kita-ku, Sapporo 060-0810, Japan;

${ }^{2}$ Laboratory of Animal Cytogenetics, Center for Advanced Science and Technology, Hokkaido University, North 10 West 8, Kita-ku, Sapporo 060-0810, Japan;

${ }^{3}$ Faculty of Science, Hokkaido University, North 10 West 8, Kita-ku, Sapporo 060-0810, Japan;

${ }^{4}$ Laboratory of Wild Animals, Department of Animal Sciences, Faculty of Agriculture, Tokyo University of Agriculture, 1737 Funako, Atsugi, Kanagawa 234-0034, Japan;

${ }^{5}$ Laboratory of Animal Genetics, Division of Applied Genetics and Physiology,

Department of Applied Molecular Bioscience, Graduate School of Bioagricultural Sciences, Nagoya University, Furocho, Chikusa-ku, Nagoya 4648601, Japan

Running title: karyotypic evolution in Apodemus

Correspondence should be addressed to: Yoichi Matsuda, Laboratory of Animal Cytogenetics, Center for Advanced Science and Technology, Hokkaido University, North 10 West 8, Kita-ku, Sapporo 060-0810 (Japan); telephone: 81-11-706-2619; fax: 81-11-736-6304; e-mail: yoimatsu@ees.hokudai.ac.jp 


\section{Summary}

We conducted comparative FISH analyses to investigate the chromosomal rearrangements that have occurred during the evolution of the rodent genus Apodemus, which inhabits broadleaf forests in the temperate zone of the Palaearctic region. Chromosome-specific painting probes of the laboratory mouse were hybridized to chromosomes of seven Apodemus species, A. agrarius, A. argenteus, A. gurkha, A. peninsulae, A. semotus, A. speciosus and A. sylvaticus, and homologous chromosomal regions were determined in the species for the study of karyotypic evolution. Differences in the hybridization patterns were found in nine pairs of autosomes among the seven species. The chromosomal location of the 5S rRNA genes on the telomeric region of chromosome 20 was highly conserved in all the species. In contrast, there was much wider variation in the location of the 18S-28S rRNA genes, although the 18S-28S rRNA genes were predominantly located on chromosomes 7, 8 and 12. Phylogenetic relationships of the seven Apodemus species were inferred from the chromosome rearrangements and the chromosomal distribution patterns of the $18 \mathrm{~S}-28 \mathrm{~S}$ rRNA genes. The karyotypic relationships correlated well with the molecular phylogeny, and $A$. semotus had the most highly conserved karyotype among the seven species.

Keyword: Apodemus, FISH, ribosomal RNA genes, karyotypic evolution, phylogeny. 


\section{Introduction}

Small rodent species belonging to the genus Apodemus are distributed throughout the Palaearctic region (Corbet 1978, Corbet \& Hill 1992, Orlov et al. 1996), and more than 20 species are now recognized in this genus (Musser \& Carleton 1993). Since all the extant species live in broadleaf forests of the temperate zone, the characteristics of habitat preferences have been inherited from their ancestors, and the radiation of the species might have been associated with global environmental changes, especially changes of flora (Serizawa et al. 2000).

There have been several studies on the phylogenetic relationships of the Apodemus species based on molecular data such as restriction fragment length polymorphism of the ribosomal RNA genes and the nucleotide sequences of the mitochondrial and nuclear genes (Suzuki et al. 1990, Chelomina et al. 1998, Serizawa et al. 2000, Michaux et al. 2002). Serizawa et al. (2000) constructed molecular phylogenetic trees of nine Apodemus species with the nucleotide sequences of the cytochrome $b(C y t b)$ gene and the interphotoreceptor retinoid binding protein $(I R B P)$ gene, and grouped them into four different lineages: the Agrarius group (A. agrarius, A. peninsulae, A. semotus and A. speciosus), Argenteus group (A. argenteus), Gurkha group (A. gurkha) and Sylvaticus group (A. alpicola, A. flavicollis and A. sylvaticus).

Comparative studies of the karyotypes in this genus have been performed using chromosomal banding techniques (Soldatovic et al. 1975, Yoshida et al, 1975, Vujosevic et al. 1984, Saitoh \& Obara 1986, Orlov et al. 1996, Reutter et al. 2001). The diploid chromosome number of most Apodemus species is $2 \mathrm{n}=46$ - 48, and their fundamental number (FN) ranges from 48 to 56 . The diversity of karyotypes has been achieved by the accumulation of chromosome rearrangements that occurred during evolution, and thus it has been possible to define the history of karyotypic changes by comparing the karyotypes among the extant species. Chromosome banding is an effective method for demonstrating 
chromosome homologies between phylogenetically related species, but the resolution using this approach is not as high as that of analysis at the molecular level.

Comparative chromosome painting is a robust method for detecting chromosome homologies at the whole chromosome level, and this approach provides clues about the processes of karyotypic evolution (Wienberg et al. 1990, Scherthan et al. 1994, Wienberg \& Stanyon 1995). The 5S and 18S-28S ribosomal RNA (rRNA) genes are good cytogenetic markers to examine interand intraspecies chromosomal variations, and in our previous study, we defined the chromosome rearrangements between the laboratory mouse (Mus musculus) and the Indian spiny mouse (M. platythrix) by comparative chromosome painting and mapping of the rRNA genes (Matsubara et al. 2003). The main event of the chromosome rearrangements between the two species was tandem fusion that occurred in the ancestral karyotype of the Mus species, and fission, reciprocal translocations and insertions were also involved.

In this study, to clarify the processes of the karyotypic changes during the evolution of seven Apodemus species, we conducted comparative chromosome painting with chromosome-specific painting probes of the laboratory mouse. The chromosomal locations of the $5 \mathrm{~S}$ and $18 \mathrm{~S}-28 \mathrm{~S}$ rRNA genes were also determined in the seven Apodemus species. The karyological data were compared with the molecular phylogenetic data, and karyotypic evolution in Apodemus is discussed.

\section{Materials and methods}

Animals, chromosome preparation and FISH

The species used in this study and the localities where they were originally collected are listed in Table 1. Agr1, Agr2, Sem1 and all animals of A. sylvaticus were bred at the Laboratory of Wild Animals, Department of Animal Sciences, Faculty of Agriculture, Tokyo University of Agriculture, Japan, and other animals 
were originally captured in the field.

Preparation of R-banded chromosomes and FISH were performed as described by Matsuda et al. (1992) and Matsuda \& Chapman (1995). Chromosome preparations were made from splenocytes or fibroblasts taken from lung tissue. The cultured cells were treated with BrdU during late $\mathrm{S}$ phase for differential replication banding. R-banded chromosomes were obtained by exposure of chromosome slides to UV light after staining with Hoechst 33258. For G-banding analysis, chromosome preparations were made from splenocytes or fibroblasts cultured without BrdU-treatment. The G-banded chromosomes were obtained with the GTG (G-bands by trypsin using Giemsa) method as described by Seabright (1971).

A $1.8-\mathrm{kb}$ and a 6.6-kb mouse genomic DNA fragment were used for chromosomal localization of the $5 \mathrm{~S}$ and $18 \mathrm{~S}-28 \mathrm{~S}$ rRNA genes, respectively (Kominami et al. 1982, Matsuda et al. 1994). The Tu89 clone used for mapping the D17Leh89 locus was a cosmid DNA clone isolated from mouse chromosome 17 by microdissection (Búcan et al. 1987).

The biotinylated chromosome-specific painting probes of the laboratory mouse were purchased from Cambio Ltd., Cambridge, UK. In situ hybridization with the painting probes was carried out following our previously reported method (Matsubara et al. 2003) with slight modification. The chromosome slides were hardened for $2 \mathrm{~h}$ at $65^{\circ} \mathrm{C}$ and denatured for $2 \mathrm{~min}$ at $70^{\circ} \mathrm{C}$ in $70 \%$ formamide, $2 \mathrm{X} \mathrm{SSC}$. The probes were denatured for $10 \mathrm{~min}$ at $75^{\circ} \mathrm{C}$ and preannealed by incubation at $37^{\circ} \mathrm{C}$ for $45 \mathrm{~min}$. The chromosome slides were hybridized with the mouse painting probes for 3 or 4 days at $37^{\circ} \mathrm{C}$. The hybridized probes were reacted with FITC-avidin (Roche Diagnostics), and then stained with propidium iodide (PI).

\section{Microphotography and image capture}

The chromosomal slides were observed under Nikon fluorescence 
microscope using Nikon filter sets B-2A and UV-2A. Kodak Ektachrome ASA100 films were used for microphotography. The digital FISH images were captured with the 550CW-QFISH application program of Leica Microsystems Imaging Solution Ltd. (Cambridge, UK) using a cooled CCD camera (MicroMAX 782Y, Princeton Instruments) mounted on a Leica DMRA microscope.

\section{Results and discussion}

\section{G-banding}

The G-banded karyotypes of the seven Apodemus species are shown in Figure 1. The karyotypes have been reported for all of these species except for $A$. gurkha (e.g., Soldatovic et al. 1975, Tsuchiya 1979, Vujosevic et al. 1984, Saitoh \& Obara 1986, Obara et al. 1997). The diploid chromosome numbers and fundamental numbers found in this study were the same as those reported previously, except regarding the B chromosomes. Polymorphism was observed in the biarmed chromosome 20 of Arg1, which resulted from a pericentric inversion in acrocentric chromosome 20 or amplification of heterochromatin on the short arm (data not shown). The G-banded patterns in chromosomes larger than chromosome 16 were similar among the species, although submetacentric chromosome 16 of A. agrarius and submetacentric chromosomes 10 and 16 of $A$. speciosus were morphologically different from the chromosomes of other species. The remaining chromosomes smaller than chromosome 17 were too small to be reliably compared by banding analysis, and their banding patterns were so different among the species that chromosome homologies could not be morphologically identified.

\section{Chromosome homology among Apodemus species}

All mouse chromosome-specific probes except for the Y chromosome probe 
successfully hybridized to chromosomes of all the Apodemus species (Figure 2). Three B chromosomes in A. peninsulae (Pen1) were not hybridized with any MMU (Mus musculus) probes (data not shown). The patterns painted with the mouse probes are summarized in Figure 1. Chromosomes of $A$. peninsulae were initially numbered according to their length since all the chromosomes were acrocentric. Each chromosome of the other six species was then numbered following the karyotype of $A$. peninsulae. The hybridization patterns were identical in 14 pairs of autosomes among the seven species. Evidence of structural changes was found in nine pairs of autosomes, chromosomes 2, 10, 16, 17, 19, 20, 21, 22 and 23. Both chromosomes 21 and 23 were painted by MMU 10 and 17. The D17Leh89 locus located on mouse chromosome 17 (Búcan et al. 1987) was mapped as a cytogenetic marker to discriminate between chromosomes 21 and 23: the chromosome that carried it was classified as chromosome 21 (Figure 1).

The proximal region of chromosome 2 was hybridized with the MMU5 probe in six species, while this region was not painted in A. argenteus (Figures 1 \& 2a). Chromosomes 11 and 22 were also hybridized with the MMU5 probe in seven species, and the size of the painted segment was almost the same among the species. These results suggest that the proximal region of chromosome 2 may have low gene density and so the nucleotide sequences have diversified in this chromosomal region of $A$. argenteus so that the hybridization intensity was too weak to detect the homologous segments with the MMU5 probe. A small segment homologous to MMU17 was detected in the proximal region of chromosome 17 in A. argenteus, while no hybridization signals were detected in six other species. A translocation might have occurred in this region of $A$. argenteus between chromosome 17 and chromosome 6 or 10 .

Chromosome 10 was submetacentric in A. speciosus, and acrocentric in the six remaining species. Chromosome 16 was submetacentric in A. agrarius and $A$. speciosus, and acrocentric in the five remaining species. Chromosome 19 was 
metacentric in A. agrarius and A. gurkha, and acrocentric in the five other species. Chromosome 20 was metacentric in A. agrarius, and acrocentric in the six other species. Chromosomes 21 and 22 were fused at the centromere in $A$. argenteus by Robertsonian translocation, and chromosome 22 was metacentric in A. speciosus, and acrocentric in the five other species. Chromosome 23 was acrocentric in A. peninsulae and A. sylvaticus, and metacentric in the five other species. However, the painting pattern was not identical in the acrocentric chromosome 23 between A. peninsulae and A. sylvaticus (Figures 1a, 1g, 2c \& 2d). In our study, the only available European species was A. sylvaticus. The morphology and the G-banding patterns of autosomes are similar among at least four European species, A. sylvaticus, A. flavicollis, A. alpicola and A. microps (Vujosevic et al. 1984, Reutter et al. 2001). In contrast, accumulation of several chromosome rearrangements has occurred in the lineage leading to A. agrarius and A. speciosus (Figure $1 \mathrm{~b} \& \mathrm{~d}$ ). Our cytogenetic data are in good accordance with the finding of Serizawa et al. (2000) that Asian species diverged earlier than European species diverged.

\section{Chromosomal locations of the ribosomal RNA genes}

Intraspecific variations were not observed in the chromosomal locations of the $5 \mathrm{~S}$ and $18 \mathrm{~S}-28 \mathrm{~S}$ rRNA genes, except that the genes were located on B chromosomes in A. agrarius and A. peninsulae (see next section). The 5S rRNA genes were localized to the telomeric region of chromosome 20 in all the species except for A. agrarius, in which the genes were localized to the centromeric regions of the $\mathrm{X}$ and $\mathrm{Y}$ chromosomes and one $\mathrm{B}$ chromosome besides chromosome 20 (Table 2 \& Figure 3a). The large hybridization signals on the $\mathrm{X}$ and $\mathrm{Y}$ chromosomes in A. agrarius suggest the possibility that the nucleotide sequence, which is homologous to the repetitive sequence in the centromeric heterochromatin of the sex chromosomes, may be contained in the spacer regions of the 5S rRNA genes, as reported in Mus species (Matsuda \& Chapman 1995, 
Matsubara et al. 2003). In our previous studies, we demonstrated that the location of the $5 \mathrm{~S}$ rRNA genes on the distal telomeric region of chromosome 8 is evolutionarily conserved among Mus species (Matsuda et al. 1994, Matsubara et al. 2003). Chromosome 20 of the Apodemus species was also painted with MMU 8 probes, indicating that the location of the 5S rRNA genes is highly conserved in Apodemus species as well as Mus species.

The chromosomal locations of the $18 \mathrm{~S}-28 \mathrm{~S}$ rRNA genes were widely different among the species (Table $2 \&$ Figures $3 b-d$ ). The distribution patterns of the 18S-28S rRNA genes in the seven species were well correlated with the phylogenetic relationships determined by Serizawa et al. (2000). In the Agrarius group and the Argenteus group of East Asia, the locations of the 18S-28S rRNA genes were relatively well conserved; the genes were predominantly located on chromosomes 7 and 8 with slight variation that was peculiar to each species (Table $2 \&$ Figure $3 b$ ). On the other hand, the genes were localized to numerous chromosomes in A. gurkha in Nepal and A. sylvaticus in the western part of the Palaearctic region (Table 2, Figures $3 c \& d$ ). The extensive distribution of the silver-stained nucleolus organizer regions (NORs) has also been reported in some European Apodemus species, including A. sylvaticus (Boeskorov et al. 1995). The locations of the 18S-28S rRNA genes appear to have been dispersed to numerous chromosomes by translocation or transposition between different chromosomes in these species. Such dispersion of the 18S-28S rRNA genes has been also reported in Mus musculus (Suzuki et al. 1990, Matsuda \& Chapman 1995) and the hominoid (Hirai et al. 1999). The 18S-28S rRNA genes originally located on chromosomes 7 and 8 (and possibly 12) in the ancestral karyotype of the Apodemus, and these genes located on chromosomes 1 - 6 and 14 and chromosomes 11, 15, 16, 21, X and Y were seen specifically in A. gurkha and A. sylvaticus, respectively. These results suggest that these genes were independently dispersed in each lineage of A. gurkha and A. sylvaticus after divergence from the Agrarius and Argenteus groups. 


\section{B chromosomes}

The presence of $\mathrm{B}$ chromosomes (Bs), which are supernumerary chromosomes other than the standard components (autosomes and sex chromosomes), has been recognized in several Apodemus species (Hayata 1973, Bekasova et al. 1980, Vujosevic \& Zivkovic 1987, Kartavtseva 1994, Obara \& Sasaki 1997, Zima et al. 1997). In this study, Bs were observed in all five individuals of A. peninsulae and one out of the three individuals of A. agrarius (Table 3). The Bs are generally considered to have originated from the autosomes and/or sex chromosomes, and to have undergone amplification of the B-specific repetitive DNA sequences (reviewed by Camacho et al. 2000). As supporting evidence for this idea, two types of repetitive DNA sequences, sequences common to both the Bs and autosomes and/or sex chromosomes, and B-specific sequences, have been obtained from several organisms. Recently, two different types of B components, B1 and B2, were obtained from A. peninsulae by microdissection (Trifonov et al. 2002). B1 chromatin contained DNA sequences that were homologous to the dispersed type of repetitive sequences of the standard components and that hybridized to most of the large Bs. On the other hand, B2 chromatin predominantly hybridized to the dot-like and small acrocentric Bs but not to the standard components. Those authors proposed that the two types of Bs originated independently in A. peninsulae. The 18S-28S rRNA genes were located on some $\mathrm{Bs}$ in all five individuals of $A$. peninsulae (Table 3 \& Figure $3 b$ ). The location of the 18S-28S rRNA genes on Bs was also reported by Boeskorov et al. (1995), who found that the Ag-stained NOR regions were localized to two metacentric Bs in an individual captured in the Ussuri Nature Reserve, Russia. The 18S-28S rRNA genes appeared to be localized to meta- or submetacentric Bs but not to dot-like and small acrocentric Bs in this study (Table 3). The results of Trifonov et al. (2002) and our study confirm that the Bs have multiple origins in this species. The 5S rRNA genes were also 
located on a B in one out of three individuals of A. agrarius (Agr3) (Table $3 \&$ Figure 3a). The hybridization signal painted on the $\mathrm{B}$ indicates that this $\mathrm{B}$ was probably derived from centromeric heterochromatin of either an $\mathrm{X}$ or $\mathrm{Y}$ chromosome with 5S rRNA genes in this species.

There are wide differences in the number of Bs and the frequency of individuals with Bs among Apodemus species, and the presence of Bs has not been found in some species (Bekasova et al. 1980, Vujosevic \& Zivkovic 1987, Kartavtseva 1994, Obara \& Sasaki 1997, Zima et al. 1997). Therefore, the origins of Bs differ between individuals as well as between species, although the possibility that the $5 \mathrm{~S}$ or $18 \mathrm{~S}-28 \mathrm{~S}$ rRNA genes transpose to some Bs from the standard components after the appearance of Bs has not been excluded. The mechanism of the appearance of $\mathrm{Bs}$ is still unknown and remains to be investigated in further studies.

\section{Karyotypic evolution of genus Apodemus}

We inferred the phylogenetic relationships of the seven Apodemus species from the chromosome rearrangements and the chromosomal distribution of the 18S-28S rRNA genes. Figure 4 shows the scheme of the karyotypic evolution in the seven species of Apodemus, assuming the most parsimonious events of chromosome rearrangements and translocations of the 18S-28S rRNA genes. The karyological relationships of the seven Apodemus species correspond well with the molecular phylogenetic tree constructed by Serizawa et al. (2000) based on the nucleotide sequences of the IRBP genes. To account for the process of the karyotypic evolution, we postulate two species that have not been found yet or do not exist at present. According to Serizawa et al. (2000), the four groups diverged within a short period ( 8 - 10 million years ago), and thus this type of divergence is regarded as adaptive radiation. It is therefore likely that the four groups diverged from one or only a few common ancestors. We speculate that the ancestral karyotype of $A$. argenteus, A. gurkha and A. sylvaticus was similar to 
that of A. semotus, i.e. 22 pairs of acrocentric chromosomes, one pair of metacentric chromosomes and sex chromosomes. The 18S-28S rRNA genes are located on chromosomes 7,8 and 12 in the former three species, whereas they are not located on chromosome 12 in A. semotus. The two types of karyotypes, in which the genes were located on chromosomes 7 and 8 or chromosomes 7,8 and 12 , were probably present as intraspecific variations in the ancestral species. In $A$. argenteus, A. gurkha and A. sylvaticus, the karyotype of each species might have originated from one chromosome rearrangement that occurred in the ancestral karyotype. The karyotype of A. peninsulae might have derived from the occurrence of one inversion followed by the appearance of Bs. It is possible that inversions in chromosomes 10 and 22 and inversions in chromosomes 19 and 20 could have occurred in the unknown species, which was derived from A. semotus by one inversion event in chromosome 16, and consequently led to the karyotypes of A. speciosus and A. agrarius, respectively.

Our karyological finding that A. semotus, an endemic species of Taiwan, retains the ancestral karyotype confirms the suggestion of Serizawa et al. (2000) that the ancestor of the extant species appeared in the forests of Central East Asia at late Tertiary. It is very likely that the ancestor of A. semotus was originally distributed in not only Taiwan but also in the continent and was superseded by new Agrarius-group species with extinction or reduction of the ancestors. Several authors have classified $A$. argenteus solely into a single group based on molecular, biochemical and morphological data (Musser et al. 1996, Serizawa et al. 2000). Several structural changes of chromosomes that were not found in six other species were observed in A. argenteus in this study. Thus, the ancestor of $A$. argenteus might have diverged much earlier than other species. The $18 \mathrm{~S}-28 \mathrm{~S}$ rRNA genes are distributed on many chromosomes in A. gurkha and A. sylvaticus, and the chromosomes with these genes are considerably different between the two species, except for chromosomes 7, 8, 12 and 22. These results suggest that the two species diverged from the common ancestor during a short period and the 
genes rapidly dispersed to numerous chromosomes. However, very little molecular cytogenetic data has been obtained for European Apodemus species, and thus further studies of the species that inhabit the western part of the Palaearctic region will be required to understand the history of their karyotypic evolution.

\section{Acknowledgements}

We are grateful to Dr. Hitoshi Suzuki, Graduate School of Environmental Earth Science, Hokkaido University, Sapporo, Japan, for genomic DNA clones of the $5 \mathrm{~S}$ and $18 \mathrm{~S}-28 \mathrm{~S}$ ribosomal RNA genes and his comments contributing to the Discussion section of this manuscript. We also thank Takashi Morita, Graduate School of Medicine, Osaka City University, Osaka, Japan, for the cosmid DNA clone of the D17Leh89 locus.

\section{References}

Bekasova TS, Vorontsov NN, Korobitsyna KV, Korablev VP (1980) Bchromosomes and comparative karyology of the mice of the genus Apodemus. Genetica 52/53: 33-43.

Boeskorov GG, Kartavtseva IV, Zagorodnyuk IV, Belyanin AN, Lyapunova EA (1995) Nucleolus organizer regions and B-chromosomes of wood mice (Mammalia, Rodentia, Apodemus). Russ J Genet 31: 156-163.

Búcan M, Herrmann B, Frischauf A-M et al. (1987) Deletion and duplication of DNA sequences is associated with the embryonic lethal phenotype of the $t^{9}$ complementation group of the mouse $t$ complex. Genes Dev 1: 376-385.

Camacho JPM, Sharbel TF, Beukeboom LW (2000) B-chromosome evolution. Phil Trans $R$ Soc Lond B 355: 163-178.

Chelomina GN, Suzuki H, Tsuchiya K, Moriwaki K, Lyapunova EA, Vorontsov 
NN (1998) Sequencing of the mtDNA cytochrome $b$ gene and reconstruction of the maternal relationships of wood and field mice of genus Apodemus (Muridae, Rodentia). Russ J Genet 34: 529-539.

Corbet GB (1978) The mammals of the Palaearctic Regions: a taxonomic review. London and Ithaca (N. Y.): British Museum (natural History), Cornell University Press.

Corbet GB, Hill JE (1992) The mammals of the Indomalayan Region: a systematic review. Oxford, New York: Oxford University Press.

Hayata I (1973) Chromosomal polymorphism caused by supernumerary chromosomes in the field mouse, Apodemus giliacus. Chromosoma 42: 403414.

Hirai H, Taguchi T, Godwin AK (1999) Genomic differentiation of $18 \mathrm{~S}$ ribosomal DNA and $\boldsymbol{\beta}$-satellite DNA in the hominoid and its evolutionary aspects. Chromosome Res 7: 531-540.

Kartavtseva IV (1994) Description of B-chromosomes in the karyotype of the field mouse Apodemus agrarius. Cytol Genet 28: 100-102.

Kominami R, Mishima Y, Urano Y, Sakai M, Muramatsu M (1982) Cloning and determination of the transcription termination site of ribosomal RNA gene of the mouse. Nucl Acids Res 10: 1963-1979.

Matsubara K, Nishida-Umehara C, Kuroiwa A, Tsuchiya K, Matsuda Y (2003) Identification of chromosome rearrangements between the laboratory mouse (Mus musculus) and the Indian spiny mouse (Mus platythrix) by comparative FISH analysis. Chromosome Res 11: 57-64.

Matsuda Y, Chapman VM (1995) Application of fluorescence in situ hybridization in genome analysis of the mouse. Electrophoresis 16: 261-272.

Matsuda Y, Harada YN, Natsuume-Sakai S, Lee K, Shiomi T, Chapman VM (1992). Location of the mouse complement factor H gene (cfh) by FISH analysis and replication R-banding. Cytogenet. Cell Genet 61: 282-285.

Matsuda Y, Moriwaki K, Chapman VM, Hoi-Sen Y, Akbarzadeh J, Suzuki H 
(1994) Chromosomal mapping of mouse 5S rRNA genes by direct Rbanding fluorescence in situ hybridization. Cytogenet Cell Genet 66: 246249.

Michaux JR, Chevret P, Filippucci M-G, Macholan M (2002) Phylogeny of the genus Apodemus with special emphasis on the subgenus Sylvaemus using the nuclear IRBP gene and two mitochondrial markers: cytochrome $b$ and $12 \mathrm{~S}$ rRNA. Mol Phylogenet Evo 23: 123-136.

Musser GG, Brothers EM, Carleton MD, Hutterer R (1996) Taxonomy and distributinal records of Oriental and European Apodemus, with a review of the Apodemus-Sylvaemus problem. Bonn Zool Beitr 46: 143-190.

Musser GG, Carleton MD (1993) Family Muridae. In: Wilson DE and Reeder DM, ed. Mammalian species of the world 2nd ed. Washington DC and London: Smithsonian Institute Press, pp 501-806.

Obara Y, Sasaki S (1997) Fluorescent approaches on the origin of B chromosomes of Apodemus argenteus hokkaidi. Chromosome Sci 1: 1-5.

Orlov VN, Bulatova, NS, Nadjafova RS, Kozlovsky A (1996) Evolutionary classification of European wood mice of subgenus Sylvaemus based on allozyme and chromosome data. Bonn Zool Beitr 46: 191-202.

Reutter BA, Nova P, Vogel P, Zima J (2001) Karyotypic variation between wood mouse species: banded chromosomes of Apodemus alpicola and A. microps. Acta Theriol 46: 353-362.

Saitoh M, Obara Y (1986) Chromosome banding patterns in five intraspecific Taxa of large Japanese field mouse, Apodemus speciosus. Zool Sci 3: 785792.

Scherthan H, Cremer T, Arnason U, Weier KU, Lima-de-Faria A, Frönicke L (1994) Comparative chromosome painting discloses homologous segments in distantly related mammals. Nature Genet 6: 342-347.

Seabright M (1971) A rapid banding technique for human chromosomes. Lancet 7731: 971-972. 
Serizawa K, Suzuki H, Tsuchiya K (2000) A phylogenetic view on species radiation in Apodemus inferred from variation of nuclear and mitochondrial genes. Biochem Genet 38: 27-40.

Soldatovic B, Savic I, Seth P, Reichstein H, Tolksdorf M (1975) Comparative karyological study of the genus Apodemus (Kaup, 1975). Acta Vet (Beograd) 25: 1-10.

Suzuki H, Kurihara Y, Kanehisa T, Moriwaki K (1990) Variation in the distribution of silver-staining nucleolar organizer regions on the chromosomes of the wild mouse, Mus musculus. Mol Biol Evo 7: 271-282.

Suzuki H, Tsuchiya K, Sakaizumi M et al. (1990) Differentiation of restriction sites in ribosomal DNA in the genus Apodemus. Biochem Genet 28: 137149.

Trifonov VA, Perelman PL, Kawada S-I et al. (2002) Complex structure of Bchromosomes in two mammalian species: Apodemus peninsulae (Rodentia) and Nyctereutes procyonoides (Carnivora). Chromosome Res 10: 109-116.

Tsuchiya K (1979) Notes on breeding of wood mouse groups for laboratory animal. Rep Hokkaido Inst Pub Health 29: 102-106 (in Japanese).

Tsuchiya K, Moriwaki K, Yosida TH (1973) Cytogenetical survey in wild population of Japanese wood mouse, Apodemus speciosus and its breeding. Exp Anim 22: 221-229.

Vujosevic M, Zivkovic S (1987) Numerical chromosome polymorphism in Apodemus flavicollis and A. sylvaticus (Mammalia: Rodentia) caused by supernumerary chromosomes. Acta Vet (Beograd) 37: 115-122.

Vujosevic M, Rimsa D, Zivkovic S (1984) Patterns of G- and C-bands distribution on chromosomes of three Apodemus species. Z Säugetierkunde 49: 234-238.

Wienberg J, Jauch A, Stanyon R, Cremer T (1990) Molecular cytotaxonomy of primates by chromosomal in situ suppression hybridization. Genomics $\mathbf{8}$ : 347-350. 
Wienberg J, Stanyon R (1995) Chromosome painting in mammals as an approach to comparative genomics. Curr Opin Genet Dev 5: 792-797.

Yoshida MC, Sasaki M, Oshimura M (1975) Karyotype and heterochromatin pattern of the field mouse, Apodemus argenteus Temminck. Genetica 45: 397-403.

Zima J, Macholán M, Slivková L (1997) Confirmation of the presence of B chromosomes in the wood mouse (Apodemus sylvaticus). Folia Zool 46: 217-221. 


\section{Figure legends}

Figure 1. G-banded karyotypes of the seven Apodemus species with comparative cytogenetic maps between the Apodemus species: A. peninsulae (a), A. agrarius (b), A. semotus (c), A. speciosus (d), A. argenteus (e), A. gurkha (f) and A. sylvaticus $(\mathrm{g})$, and the laboratory mouse. There have been no reports of detailed standard karyotypes of Apodemus species, and therefore chromosomes of $A$. peninsulae were numbered according to their length, and chromosomes of the six other species were numbered according to their homology to A. peninsulae chromosomes. The numbers of mouse chromosomes homologous to Apodemus chromosomes are indicated to the right of the chromosomes of each species. Arrows and arrowheads indicate the regions to which the following genomic clones were hybridized: the D17Leh89 loci (black arrows), the 5S rRNA genes (white arrowheads), and the 18S-28S rRNA genes (black arrowheads).

Figure 2. FISH patterns obtained with mouse chromosome-specific painting probes. (a, b, d) Chromosome painting with the MMU 5 probe in A. peninsulae (Pen1) (a), and MMU 17 probe in A. peninsulae (Pen1) (c) and A. sylvaticus (Syl1) (d). Hybridization signals were visualized using FITC-avidin on R-banded chromosomes stained with PI. (b) Hoechst-stained G-banded pattern of the same metaphase of (a). (a) Arrows indicate the hybridization signals with MMU 5 on the proximal regions of chromosome 2. (c, d) Arrows indicate that the hybridization patterns with MMU 17 on chromosome 23 are different between $A$. peninsulae (c) and A. sylvaticus (d). Scale bars indicate $10 \mu \mathrm{m}$.

Figure 3. FISH patterns with genomic DNA clones of the $5 \mathrm{~S}$ (a) and 18S-28S (b - d) rRNA genes. Chromosomal localization of the 5S rRNA genes in A. agrarius (Agr3) (a), and the 18S-28S rRNA genes in A. peninsulae (Pen2) (b), A. sylvaticus (Syl1) (c) and A. gurkha (Gur1) (d). Hybridization signals were visualized by FITC-avidin on PI-stained chromosomes. Arrowheads indicate the 
hybridization signals on autosomes and sex chromosomes. (a, b) Arrows indicate the hybridization signals of the $5 \mathrm{~S}$ (a) and $18 \mathrm{~S}-28 \mathrm{~S}$ (b) rRNA genes on $\mathrm{B}$ chromosome(s). Scale bars indicate $10 \mu \mathrm{m}$.

Figure 4. Phylogenetic relationships of the seven Apodemus species inferred from the chromosome rearrangements and the chromosomal distribution of 18S28S rRNA genes. The chromosome numbers under each species name indicate the chromosomes to which the $18 \mathrm{~S}-28 \mathrm{~S}$ rRNA genes were localized. The type of chromosome rearrangements that occurred between two species is indicated on the side of each branch. In and $\mathrm{Rb}$ indicate inversion and Robertsonian translocation, respectively. 
Table 1. Species used in this study, their diploid chromosome numbers (2n) and fundamental numbers (FN).

\begin{tabular}{|c|c|c|c|c|c|}
\hline Species & Common name & $2 n$ & $\begin{array}{c}\text { FN excluding } \\
\mathrm{B}(\mathrm{s})\end{array}$ & Specimen $^{\mathrm{b}}$ & Collection locality \\
\hline \multirow[t]{3}{*}{ A. agrarius } & Striped field mouse & $48+B(s)$ & 56 & Agr1 (우) & Korea \\
\hline & & & & $\operatorname{Agr} 2\left(\sigma^{7}\right)$ & Korea \\
\hline & & & & Agr3 (우) & Vladivostok, Russia \\
\hline \multirow[t]{5}{*}{ A. peninsulae } & Korean field mouse & $48+B(s)$ & 48 & Pen1 (ه্) & Ussrisk, Russia \\
\hline & & & & $\operatorname{Pen} 2\left(\sigma^{\top}\right)$ & Hokkaido, Japan \\
\hline & & & & Pen3 (ơ) & Vladivostok, Russia \\
\hline & & & & Pen4 (ơ) & Vladivostok, Russia \\
\hline & & & & Pen5 (ه) & Khasan, Russia \\
\hline \multirow[t]{2}{*}{ A. semotus } & Taiwanese field mouse & 48 & 50 & $\operatorname{Sem} 1\left(\sigma^{\top}\right)$ & Taiwan \\
\hline & & & & $\operatorname{Sem} 2\left(\sigma^{7}\right)$ & Taiwan \\
\hline \multirow[t]{4}{*}{ A. speciosus } & Large Japanese field mouse & 46 or $48^{a}$ & 56 & Spe1 (우) & Ibaraki, Japan \\
\hline & & & & Spe2 (ত্ত) & Miyazaki, Japan \\
\hline & & & & Spe3 (우) & Hokkaido, Japan \\
\hline & & & & Spe4 (우) & Shizuoka, Japan \\
\hline \multirow[t]{4}{*}{ A. argenteus } & Small Japanese field mouse & $46+B(s)$ & 51 (ه্ত); 52 (우) & $\operatorname{Arg} 1$ (ه) & Miyazaki, Japan \\
\hline & & & & $\operatorname{Arg} 2\left(\sigma^{7}\right)$ & Kagawa, Japan \\
\hline & & & & $\operatorname{Arg} 3\left(\sigma^{7}\right)$ & Shizuoka, Japan \\
\hline & & & & Arg4 (우) & Yakushima, Japan \\
\hline A. gurkha & Himalayan field mouse & 48 & 52 & Gur1 (ه্) & Nepal \\
\hline \multirow[t]{3}{*}{ A. sylvaticus } & Wood mouse & $48+B(s)$ & 48 & Syl1 (די) & Switzerland \\
\hline & & & & Syl2 (דים) & Germany \\
\hline & & & & Syl3 (우) & Belgium \\
\hline
\end{tabular}

a Two chromosomal races exist (Tsuchiya et al. 1973).

${ }^{\mathrm{b}}$ The individual with the first I.D. number was used for both chromosome painting and chromosome mapping of the $5 \mathrm{~S}$ and $18 \mathrm{~S}-28 \mathrm{~S}$ rRNA genes in each species. Other individuals were only used for chromosome mapping of the rRNA genes. 
Table 2. Chromosomal distribution of the $5 \mathrm{~S}$ and 18S-28S rRNA genes.

\begin{tabular}{llcc}
\hline Group $^{\mathrm{a}}$ & Species & SS rRNA $^{\mathrm{b}}$ & 18S-28S rRNA $^{\mathrm{b}}$ \\
\hline Agrarius & A. agrarius & $20, \mathrm{X}, \mathrm{Y}, \mathrm{B}$ & $7,8,22$ \\
& A. peninsulae & 20 & $7,8, \mathrm{~B}(\mathrm{~s})$ \\
& A. semotus & 20 & 7,8 \\
& A. speciosus & 20 & 7 \\
Argenteus & A. argenteus & 20 & $7,8,12$ \\
Gurkha & A. gurkha & 20 & $1,2^{\mathrm{c}}, 3,4,5,6,7,8,12,14^{\mathrm{c}}, 22$ \\
Sylvaticus & A. sylvaticus & 20 & $7,8,11,12,15,16,21,22, \mathrm{X}, \mathrm{Y}$ \\
\hline
\end{tabular}

${ }^{a}$ Grouping of species was made according to Serizawa et al. (2000).

${ }^{\mathrm{b}}$ The chromosomal regions at which the genes are located are shown in Figure 1.

${ }^{\mathrm{c}}$ The genes are located in a nonhomogeneous manner. 
Table 3. Numbers of B chromosomes and the morphologies of B chromosomes with the 5S or $18 \mathrm{~S}-28 \mathrm{~S}$ rRNA genes in five A. peninsulae individuals and one A. agrarius individual.

\begin{tabular}{|c|c|c|c|c|c|}
\hline \multirow{2}{*}{ Species } & \multirow{2}{*}{ Specimen } & \multirow{2}{*}{$\begin{array}{c}\text { No. of } \\
\mathrm{B}(\mathrm{s})\end{array}$} & \multicolumn{3}{|c|}{ Classification* } \\
\hline & & & 5S rRNA & 18S-28S rRNA & No rRNA \\
\hline \multirow[t]{5}{*}{ A. peninsulae } & Pen1 & 3 & & Medium m/sm (1), Small m/sm (1) & $\mathrm{d}(1)$ \\
\hline & Pen2 & 7 & & Medium m/sm (4) & Small a (3) \\
\hline & Pen3 & 2 & & Small m/sm (1), d (1) & \\
\hline & Pen4 & 4 & & Medium m/sm (2), Small m/sm (2) & \\
\hline & Pen5 & 1 & & Large $\mathrm{m}(1)$ & \\
\hline A. agrarius & Agr3 & 1 & $\mathrm{~d}(1)$ & & \\
\hline
\end{tabular}

$\mathrm{m}$, metacentric chromosome; $\mathrm{m} / \mathrm{sm}$, meta- or submetacentric chromosome; a, acrocentric chromosome; $\mathrm{d}$, dot-like chromosome

* The numbers of chromosomes are shown in the parentheses. 
a $\quad$ A. peninsulae (Pen5)

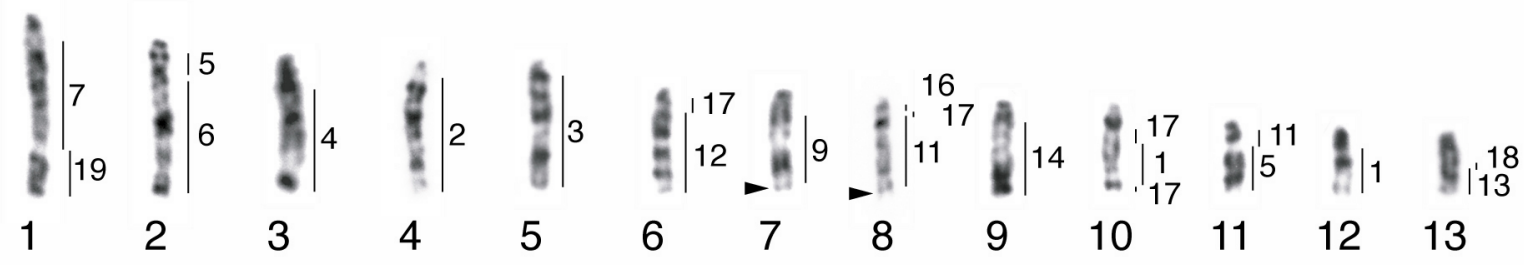

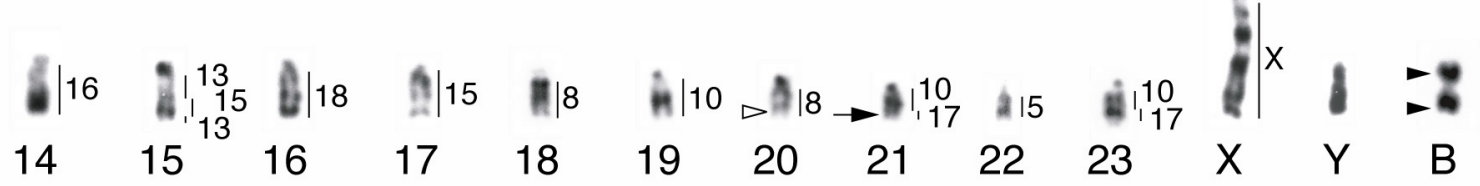

b A. agrarius (Agr1)

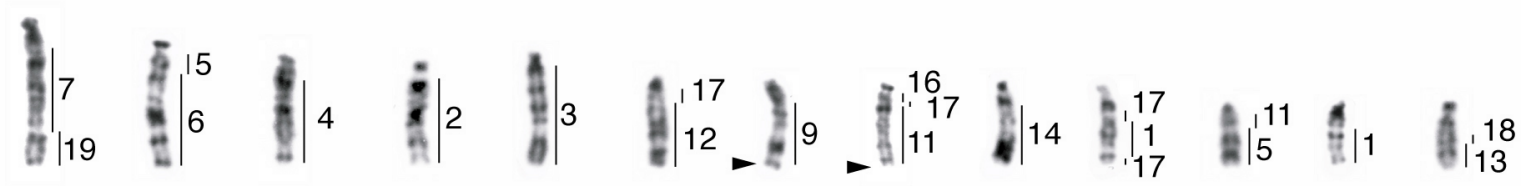

$\begin{array}{lllllllllllll}1 & 2 & 3 & 4 & 5 & 6 & 7 & 8 & 9 & 10 & 11 & 12 & 13\end{array}$

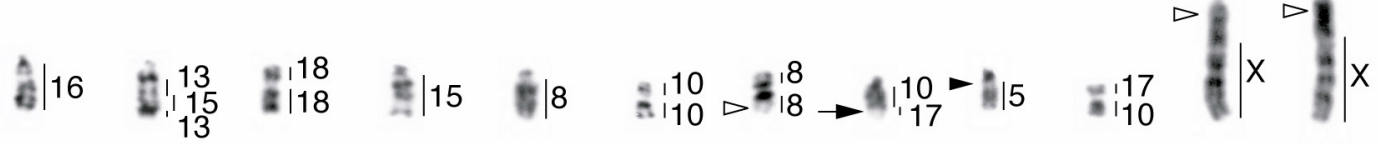

$\begin{array}{llllllllllll}14 & 15 & 16 & 17 & 18 & 19 & 20 & 21 & 22 & 23 & X & X\end{array}$

C A. semotus (Sem1)

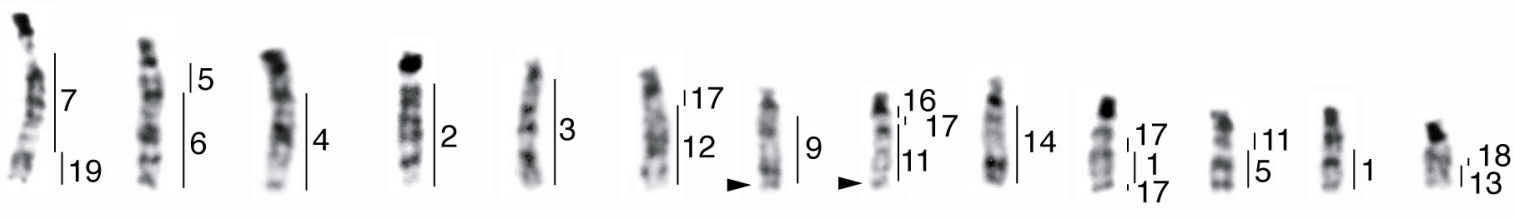

$\begin{array}{lllllllllllll}1 & 2 & 3 & 4 & 5 & 6 & 7 & 8 & 9 & 10 & 11 & 12 & 13\end{array}$

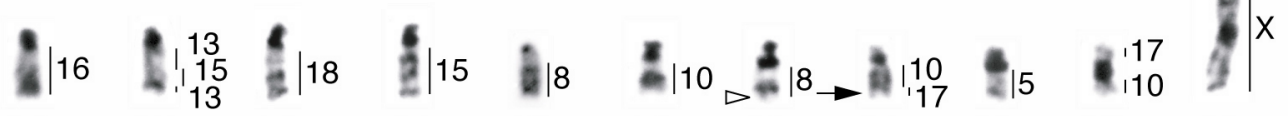

$\begin{array}{llllllllllll}14 & 15 & 16 & 17 & 18 & 19 & 20 & 21 & 22 & 23 & X & Y\end{array}$

Figure 1 
d

A. speciosus (Spe4)

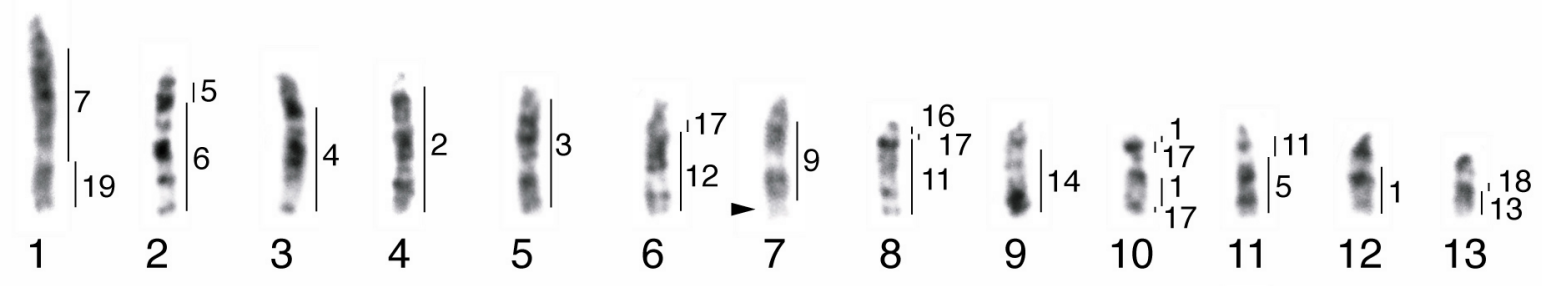

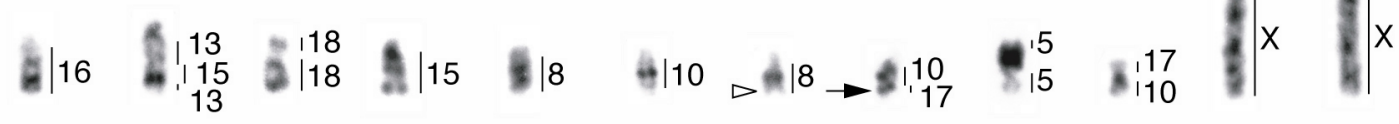
$\begin{array}{llllllllllll}14 & 15 & 16 & 17 & 18 & 19 & 20 & 21 & 22 & 23 & \mathrm{X} & \mathrm{X}\end{array}$

e A. argenteus (Arg3)

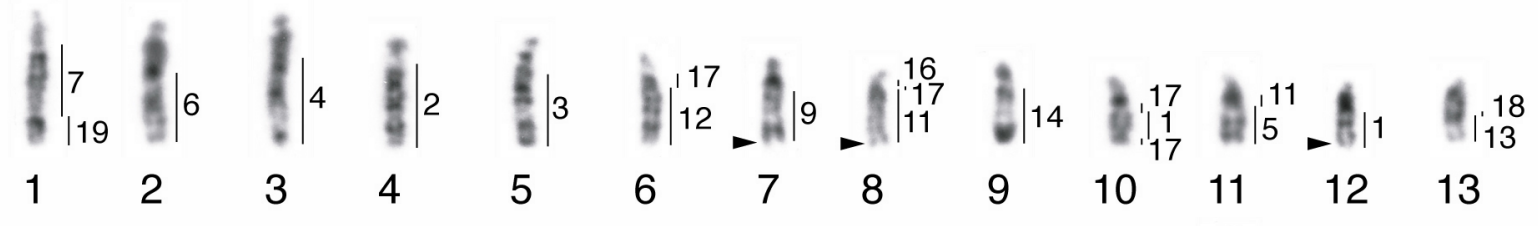

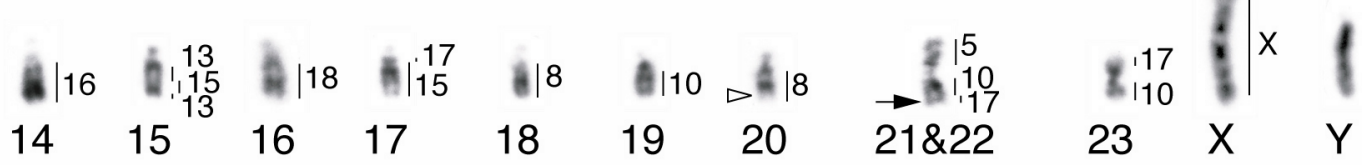

f $\quad$ A. gurkha (Gur1)

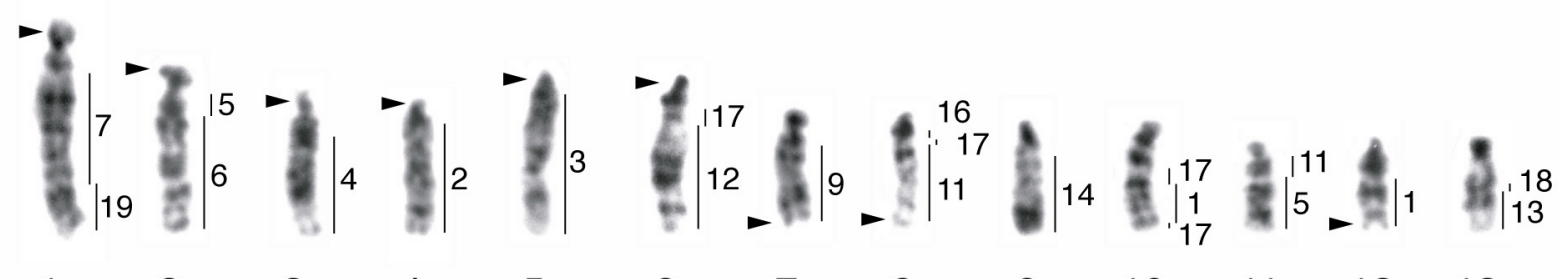

$\begin{array}{lllllllllllll}1 & 2 & 3 & 4 & 5 & 6 & 7 & 8 & 9 & 10 & 11 & 12 & 13\end{array}$

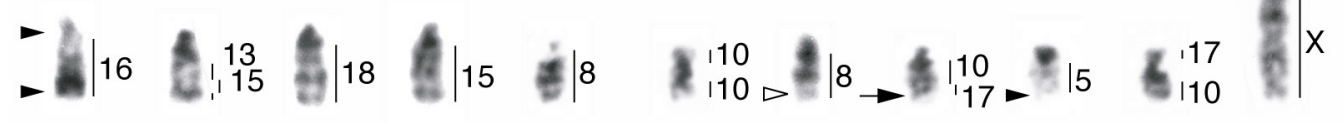
$\begin{array}{llllllllllll}14 & 15 & 16 & 17 & 18 & 19 & 20 & 21 & 22 & 23 & X & Y\end{array}$

Figure 1 continued 1 


$$
\begin{aligned}
& \text { g A. sylvaticus (Syl1) }
\end{aligned}
$$

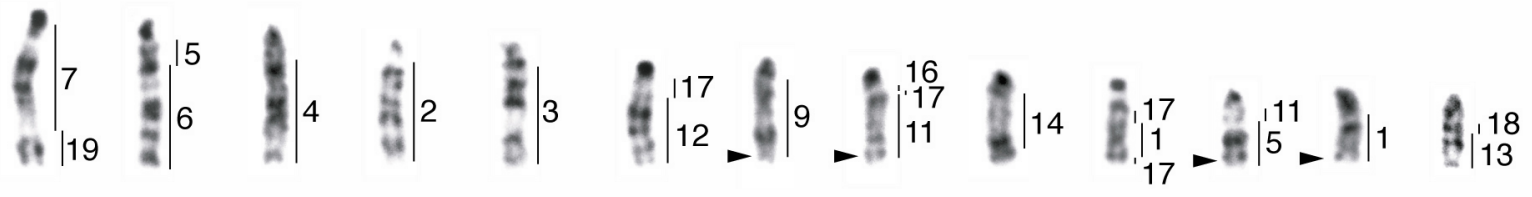

$$
\begin{aligned}
& \begin{array}{lllllllllllll}
1 & 2 & 3 & 4 & 5 & 6 & 7 & 8 & 9 & 10 & 11 & 12 & 13
\end{array}
\end{aligned}
$$

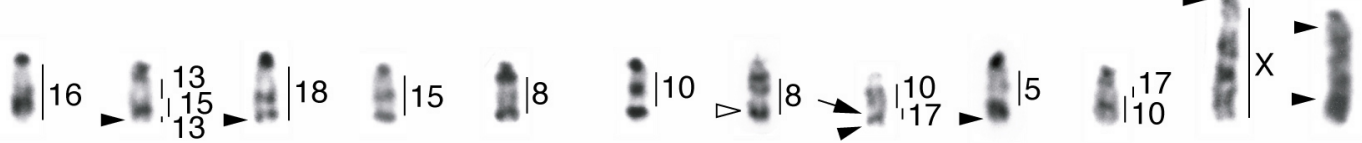

$$
\begin{aligned}
& \begin{array}{llllllllllll}
14 & 15 & 16 & 17 & 18 & 19 & 20 & 21 & 22 & 23 & X & Y
\end{array}
\end{aligned}
$$

Figure 1 continued 2 

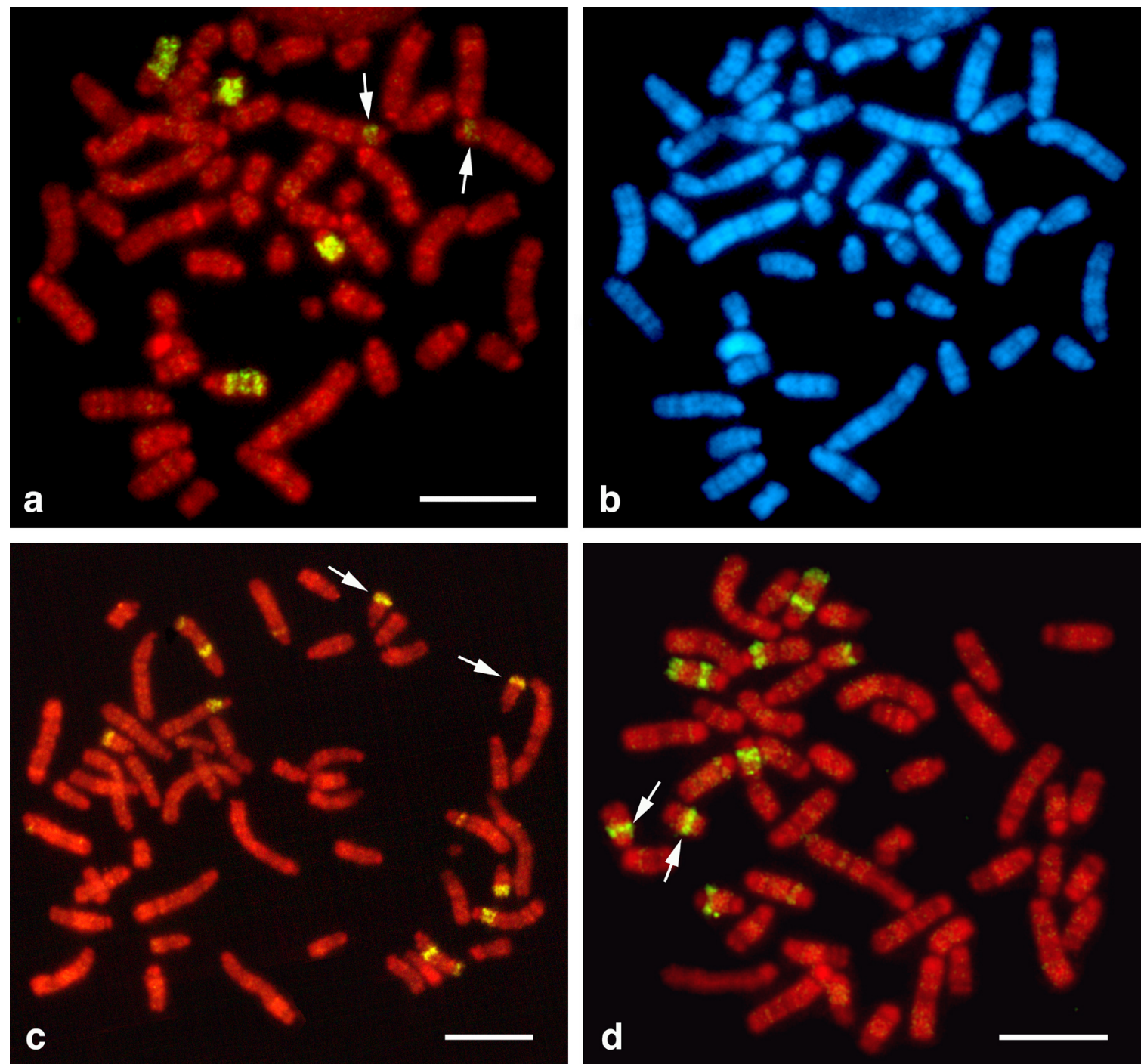

Figure 2 

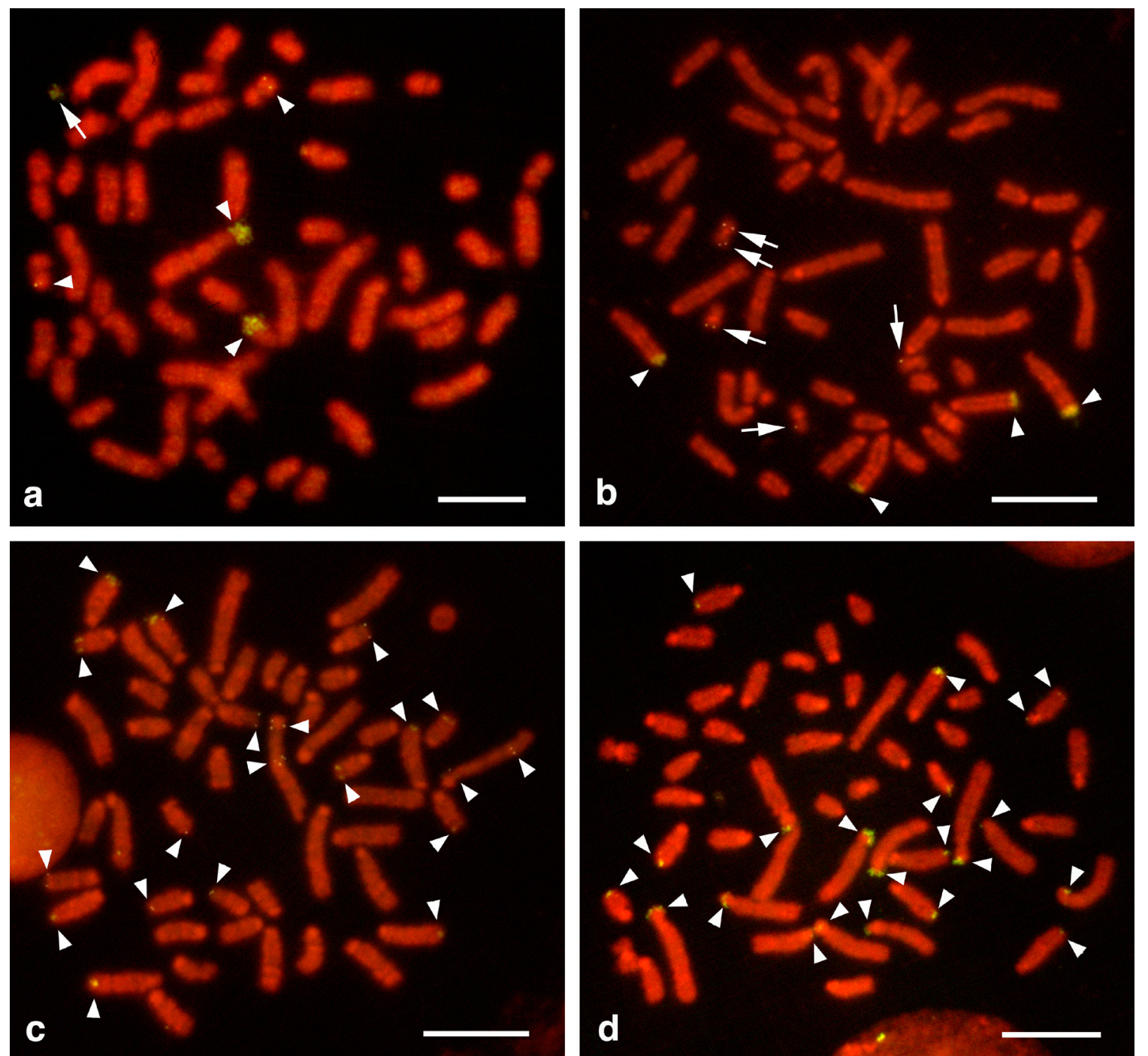

Figure 3 


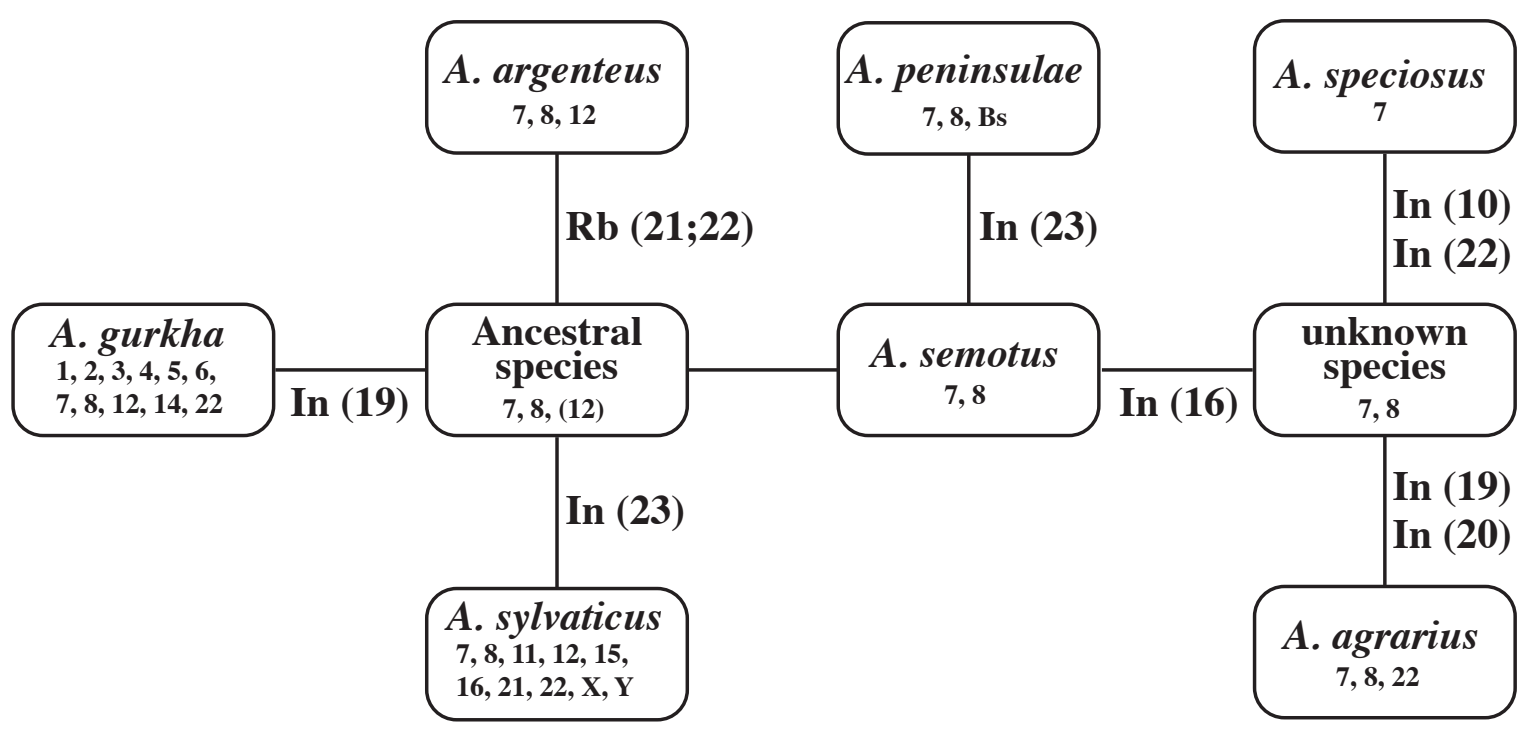

Figure 4 